\title{
Drug-facilitated sexual assault
}

\author{
Bernadette Butler MB BS, Jan Welch MB BS BSc
}

$\infty$ See related research paper by Du Mont and colleagues, page 513

$\mathrm{T}$ he contribution of alcohol and other drugs to sexual assault has been increasingly recognized during the last 15-20 years. This phenomenon has various names, including drug-facilitated sexual assault, drug-andalcohol facilitated rape, and incapacitated rape. Drug-facilitated sexual assault is also often referred to as "date rape" or "drug rape," but these terms are not interchangeable. Operation Matisse, a prospective study in the United Kingdom, distinguished between "opportunistic" drug-facilitated sexual assault, in which the alleged assailant takes advantage of someone who has voluntarily ingested drugs or alcohol, and "proactive" drugfacilitated sexual assault, in which the alleged assailant intentionally administers drugs or alcohol to the victim. ${ }^{1}$

In this issue, Du Mont and colleagues ${ }^{2}$ report the findings from a prospective study of the prevalence and risk factors associated with suspected drug-facilitated sexual assault. Their inclusion criteria were based on features of the victims' presentation rather than toxicological analysis. The authors report that $20.9 \%$ of victims of sexual assault met the criteria for drug-facilitated sexual assault. These victims were more likely than victims of other types of sexual assault to present to a large urban centre, to have consumed overthe-counter medications and street drugs in the 72 hours before the suspected assault, and to have consumed alcohol before the assault.

Many drugs, alone or in combination, have the potential to be used to facilitate sexual assault, including alcohol, benzodiazepines, antihistamines, antidepressants, marijuana, cocaine and gamma-hydroxybutyrate (GHB)., ${ }^{1,3,4}$ This list is extensive and is growing as new drugs become available and new interactions are identified. Whether taken voluntarily or involuntarily, such drugs are often metabolized and excreted before the victim even perceives that a sexual assault may have occurred. ${ }^{1,3}$ In turn, this contributes to the underreporting of drug-facilitated sexual assault.

The findings by Du Mont and colleagues support the view that alcohol plays a major role in drug-facilitated sexual assault. Previously, Weir noted that cases of drug-facilitated sexual assault were frequently found to involve alcohol, marijuana or cocaine, and were less likely to involve drugs, such as flunitrazepam (Rohypnol) and gammahydroxybutyrate, that are commonly described as being used in this context. ${ }^{5}$ Similar findings have been reported by others, ${ }^{1}$ including Hall and colleagues ${ }^{3}$ in a recent retrospective study from Northern Ireland.

For clinicians caring for victims of sexual assault, a nonjudgemental approach is essential. It is important to recognize the possibility of drug-facilitated sexual assault and provide the necessary therapeutic care while addressing forensic is-

\section{Key points}

- Alcohol and drugs are common contributors to sexual assault.

- Clinicians providing care to victims of sexual assault should take early evidence samples for toxicology and DNA evidence where possible.

- Forensic examination should address the different possible types of sexual assault.

- Preventive efforts should focus on providing education aimed at reducing the incidence of drug-facilitated sexual assault.

sues when possible, including evidence collection and documentation. Necessary interventions may include providing life support measures, emergency contraception, prophylaxis for sexually transmitted infections and psychosocial support, as well as managing injuries. ${ }^{4,6,7}$

The types of forensic or medicolegal samples that are appropriate to obtain for toxicologic examination after drugfacilitated sexual assault depend on the time of presentation. Early after the assault, urine and blood (and in some jurisdictions, saliva) can be analyzed to detect alcohol and drugs. For later presentations, hair samples may be used for drug identification. ${ }^{4}$ The increasing availability of early evidence kits, which contain material for taking early urine samples and a mouth rinse or swab, may improve the early collection of evidence. Other valuable samples for forensic testing may include chewing gum, clothing and feminine hygiene products. Consideration should also be given to performing a forensic medical examination to obtain DNA and other evidence, and addressing the different potential types of assault (e.g., penile penetration of the mouth, vagina or anus; penetration with an object; or sexual touching)., ${ }^{4,6,7}$ This could, however, cause distress to patients who may not have considered what sort of sexual acts might have taken place, and obtaining valid informed consent before any type of examination is crucial.

If an individual's memory is incomplete or absent, she or he may expect that clinical examination and forensic tests will determine exactly what has happened. After all, that is what is shown on so many television crime investigation programs. It is therefore imperative that clinicians explain the limitations of both clinical examination and forensic testing. Even if no evidence of sexual assault is found, this does not mean that nothing happened. It may be very difficult for some patients to accept that "blank memory" may never be regained or that information about lost time may not be forthcoming. Such

Bernadette Butler and Jan Welch are with the Haven Camberwell, King's College Hospital, NHS Foundation Trust, Denmark Hill, London, UK 
factors may affect psychological recovery, which can also be influenced by elements such as recollections of smell and touch without visual memory and by other people's views of an assault that the victim cannot recall., ${ }^{4.8}$

As with many aspects of health care, prevention is better than cure. Efforts must focus on reducing the risk of sexual assault and drug-facilitated sexual assault. The fact that alcohol is easily, and often cheaply, available and is a major risk factor for sexual assault should be addressed specifically by increasing awareness and education. Collaborative efforts among stakeholders may assist in achieving this. Electronic communication methods may be helpful for disseminating health care fact sheets, advice on university websites, and links to social networking sites. Education should be aimed at men as well as women, so that both recognize their potential vulnerability, not only as victims but also as possible assailants. Useful educational elements may include awareness of the different biological response of women and men to alcohol, the consequences of mixing drugs, whatever their provenance, and approaches to staying safer and thereby minimizing risk.

Health care systems, criminal justice systems and volunteer agencies, among others, may all deal with sexual assault. It is essential for everyone involved in dealing with sexual assault to work in partnership to provide holistic services centred on the needs of the victim.
Competing interests: None declared.

Contributors: Bernadette Butler wrote the first draft of the manuscript. Both of the authors revised the manuscript for intellectual content and approved the version submitted for publication.

\section{REFERENCES}

1. Gee D, Owen P, McLean I, et al. Operation MATISSE: investigating drug facilitated sexual assault. London (UK): The Association of Chief Police Officers (ACPO); 2006. Available: www.acpo.police.uk/asp/policies/Data/Operatin \%20Matisse\%20report\%20-\%20press\%20rel.\%2084.doc (accessed 2008 Dec. 29).

2. Du Mont J, Macdonald S, Rotbard N, et al. Factors associated with suspected drugfacilitated sexual assault. CMAJ 2009;180:513-9.

3. Hall J, Goodall EA, Moore T. Alleged drug facilitated sexual assault (DFSA) in Northern Ireland from 1999 to 2005. A study of blood alcohol levels. J Forensic Leg Med 2008;15:497-504.

4. Marc B. Current clinical aspects of drug-facilitated sexual assaults in sexually abused victims in a forensic emergency unit. Ther Drug Monit 2008;30:218-24.

5. Weir E. Drug-facilitated date rape. CMAJ 2001;165:80.

6. World Health Organization. Guidelines for medico-legal care for victims of sexual violence. Geneva (Switzerland): The Organization; 2004. Available: http://whqlibdoc .who.int/publications/2004/924154628X.pdf (accessed 2009 Jan. 13).

7. Welch J, Mason F. Rape and sexual assault. BMJ 2007;334:1154-8.

8. Gauntlett-Gilbert J, Keegan A, Petrak J. Drug facilitated sexual assault: cognitive approaches to treating trauma. Behav Cogn Psychother 2004;32:215-23.

Correspondence to: Dr. Jan Welch, the Haven Camberwell, King's College Hospital, NHS Foundation Trust, Denmark Hill, London, United Kingdom SE5 9RS; fax 0203299 3486; Jan.Welch@kch.nhs.uk

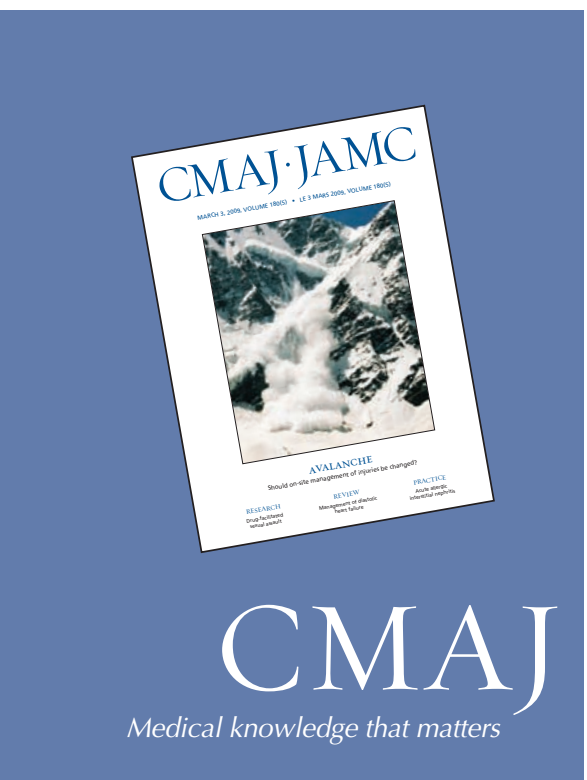

3000 volunteer reviewers from around the world are the foundation for CMAJ's thorough, criteria-based review process. The editorial staff includes scientific consultants with expertise in statistics, experimental design and epidemiology.

\section{To order your copy,} call the CMA Member Service Centre tel $888855-2555$ or $613731-8610 \times 2307$ fax 613 236-8864 cmamsc@cma.ca

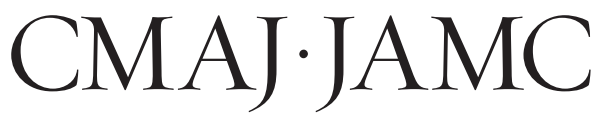

